TEACHER RECOMMENDATION AND INEQUALITY

\title{
Are tracking recommendations biased? A review of teachers' role in the creation of inequalities in tracking decisions
}

\author{
Anatolia Batruch ${ }^{12}$ \\ Sara Geven ${ }^{2}$ \\ Emma Kessenich ${ }^{2}$ \\ Herman van de Werfhorst ${ }^{2}$ \\ ${ }^{1}$ University of Lausanne \\ ${ }^{2}$ University of Amsterdam
}

\begin{abstract}
Authors Note
Anatolia Batruch and Sara Geven contributed equally to the manuscript and share first authorship. This study was supported by the Netherlands Organization for Scientific Research (NWO) through a Vici grant awarded to Herman van de Werfhorst (\#453-14-017) and a Veni grant awarded to Sara Geven (\#016.Veni.195.125).
\end{abstract}

This paper is not the copy of record and may not exactly replicate the final, authoritative version of the article.

Please do not copy or cite without authors' permission. 


\title{
TEACHER RECOMMENDATION AND INEQUALITY
}

\begin{abstract}
Sorting students into hierarchically ordered tracks or streams on the basis of their academic performance (i.e., tracking) is ubiquitous in educational systems, and oftentimes based on teachers' track recommendations. International surveys indicate that tracking is associated with educational inequalities. To determine if inequalities in tracking may be due to teacher recommendations being biased against students from disadvantaged socio-economic and/or ethnic backgrounds, we conducted a systematic review of 26 recent articles on tracking recommendations and students' socio-economic or ethnic background. We find that teacher recommendations are biased against students from disadvantaged socio-economic backgrounds, yet evidence with respect to ethnic biases is more mixed. We also conducted an integrative review to examine which factors may account for social and ethnic inequalities in teacher tracking recommendations. We conclude that students', parents' and teachers' attitudes and behaviours play a role in tracking recommendations but cannot fully account for the inequality in these recommendations. We discuss promising areas for future study, and argue that research may want to focus on finding institutional moderators in order to combat biases in educational institutions.
\end{abstract}

Keywords: teachers, educational inequality, ability tracking, teacher expectations, track recommendations

\section{Highlights}

- Teacher recommendations are biased against students from disadvantaged socioeconomic background, even when performance is controlled for.

- The evidence for ethnic bias in teacher tracking recommendation is more mixed

- Students, teachers or parents' attitudes or behaviors affect tracking recommendations but do not appear to (fully) mediate inequality in tracking recommendation.

- To combat biases in teacher recommendation, research should focus on finding institutional or situational moderators of the effect instead of individual-level mediators. 


\section{TEACHER RECOMMENDATION AND INEQUALITY}

\section{Introduction}

In most educational systems, students are sorted into different educational programs on the basis of their academic performance. The objective of this so-called tracking is to enhance the efficiency of education, as it enables schools and teachers to tailor the pace and content of the educational material to fit students' academic needs (Van de Werfhorst \& Mijs, 2010). Whereas in the United States students tend to be tracked for specific courses (i.e., within-school tracking), in multiple countries in continental Europe, students are tracked into entirely different schools or classrooms for their full curriculum (i.e., between-school tracking) (Chmielewski, 2014). Because the consequences of tracking policies can be extensive for both students and societies (e.g., labor market structure), the effects of tracking have garnered the attention of many researchers in the social and educational sciences (Gamoran, 2009).

\subsection{Inequality in tracking}

One of the most prolific research area in tracking has focused on its impact on the reproduction of social inequalities. Various studies suggest that educational systems that are characterized by higher levels of between-school tracking are marked by stronger socio-economic and ethnic inequalities in achievement and attainment (Brunello \& Checchi, 2007; Van de Werfhorst \& Mijs, 2010). Moreover, research indicates that students from disadvantaged socioeconomic backgrounds consistently attend lower ability tracks (Organisation for Economic Co-operation and Development [OECD],2011).

Historically, research has explained educational inequalities by the lower ability levels of disadvantaged groups, as well as their choice for less ambitious educational pathways (Kloosterman et al., 2009; Van de Werfhorst \& Hofstede, 2007). However, educational inequalities may not only stem from mechanisms operating at the student- or family-level, but could also find 


\section{TEACHER RECOMMENDATION AND INEQUALITY}

their origin in school-level mechanisms (Dumont et al., 2019; Esser, 2016). In many betweenschool tracking countries, teachers' track recommendations play an important role in students' track placements (Boone \& Van Houtte, 2013; Dumont et al., 2019; Pietsch \& Stubbe, 2007). More recently, researchers have started to include biases in teacher expectations as a third potential mechanism underlying inequalities in educational attainment and achievement in educational systems characterized by between-school tracking (Dumont et al., 2019; Esser, 2016).

\subsection{Inaccuracy of teachers' judgements}

While there aren't any reviews that directly examine biases in tracking recommendation (Wenz \& Hoenig, 2020), there are review and meta-analytic studies on an important related topic: teacher judgements and expectations. They demonstrate that teachers' judgements and expectations are correlated with students' academic abilities, yet a significant part of the variance remains unexplained. For example, a meta-analysis on 73 studies shows an overall mean effect size of 0.63 between teacher judgements and student achievement at standardized test scores (Südkamp et al., 2012). This implies that teacher judgements do not perfectly resemble student performance, and more than $40 \%$ of the variance may be attributed to teachers' reliance on nonacademic information. A more recent review study concludes that the accuracy of teacher judgements tends to be quite high with respect to students' academic achievement and intelligence, yet is substantially lower for outcomes that can indirectly contribute to students' educational success, such as judgements about student creativity, memory, meta-cognition, social skills and learning motivation (Urhahne \& Wijnia, 2020). This can have important implications for biases in track recommendations, as teachers often base their recommendations on more than academic achievement and intelligence alone (Boone \& Van Houtte, 2013; Vanlommel \& Schildkamp, 2018). Importantly, a recent review study finds that teacher expectations are related to students' 


\section{TEACHER RECOMMENDATION AND INEQUALITY}

socio-economic status (Wang et al., 2018). Together these findings suggest that in countries in which teachers' judgements and expectations are used to make tracking decision, teachers may contribute to the creation of educational inequalities by making systematic errors for or against students' belonging to specific social groups.

\subsection{Present study}

Despite its interest to researchers in the social and educational sciences, no review has yet examined the existence and sources of socio-economic and ethnic inequalities in teacher tracking recommendations. For this purpose, we conduct a systematic and an integrative review in which we aim to answer the following two research questions: 1) How do a student's social and ethnic background impact teachers' between-school track recommendations, and 2) Which factors can potentially account for social and/or ethnic biases in tracking recommendations? In this study, we define biases as systematic discrepancies in teachers' recommendations for equally performing students from different socio-economic and/or ethnic backgrounds (Axt \& Lai, 2019).

To examine how a student's social and ethnic background impact teachers' between-school tracking recommendations, we conduct a systematic review of 26 recent (from 2000 onward) observational and experimental quantitative studies. To address the sources of social and/or ethnic inequality in teacher tracking recommendations, we discuss factors that could explain why teachers provide biased recommendations. We distinguish three types of factors that may explain biased teacher track recommendations: student and parent-related, teacher-related, and institutional factors. 


\section{TEACHER RECOMMENDATION AND INEQUALITY}

\section{Methods}

\subsection{Search and selection procedure}

We conducted a systematic literature search via Web of Science. This database was chosen due to its advanced search options and its interdisciplinary profile, given that our topic of interest combines insights from psychology, educational sciences, sociology, and economics. We used a concatenated search string to trawl through the abstracts of all available documents that were published since 1 January 2000 and that were written in English: $\mathrm{AB}=(($ "teacher* recommend*") OR ("school*placement recommend*") OR (track* AND teacher*) OR (allocat* AND teacher*) OR ("school*placement" AND teacher*) OR ("teacher* expect*") OR ("teacher* bias*") OR ("teacher* judg*")). The concatenation was necessary as the terms used by scholars to refer to track recommendations vary widely.

The definitive search was conducted in June 2020, yielding a total of 2,771 results. All results were saved and screened in a two-step process, using the Rayyan systematic review software. In the first screening phase, all studies were categorized as either 'irrelevant' or 'potentially relevant', based on their titles and, where necessary, abstracts. In this stage, studies were only excluded if they were clearly irrelevant content-wise, such as studies that matched the search criteria because they employed an eye-tracking methodology. This was followed by a second screening phase, in which those 422 studies that had previously been identified as being 'potentially relevant' were coded inductively, based on their abstract and, if necessary, methods section. In this second phase, purely qualitative studies were excluded $(\mathrm{N}=71)$ and quantitative studies were categorized on the basis of their dependent variable, resulting in five categories (see Table 1). Multiple categorizations were possible, meaning that studies which encompassed analyses with different dependent variables can appear in multiple categories. Given our review's 


\section{TEACHER RECOMMENDATION AND INEQUALITY}

focus on track recommendations, we further considered only those studies that use teacher track recommendations as (one of) their dependent variable(s) $(\mathrm{N}=42)$.

[ Table 1 about here]

To get a more comprehensive list of studies on teacher track recommendations, we screened the full reference lists of all the articles using track recommendations as (one of) their dependent variable(s). After parsing and de-duplicating the references, we applied an equivalent two-step screening procedure to identify studies that were published since 2000 , were written in English, had not yet been included in our systematic search results, employed a quantitative methodology, and analysed teacher track recommendations as a dependent variable. This led to an additional 37 studies (total $\mathrm{N}=79$ ).

To make a final selection for our review, we evaluated the full texts of all these 79 studies against the following more detailed in- and exclusion criteria:

1) The use of original data (i.e., no reviews or meta-analyses);

2) The analysis of between-school track recommendations (i.e., no within-school track recommendations for, for example, advanced mathematics or gifted programmes; no analysis of student's or parent's track choice rather than the teachers' recommendation)

3) The inclusion of a measure of a student's socio-economic status (SES) and/or ethnic/migration background, measured at the student level ${ }^{3}$;

4) The inclusion of standardized test scores or grades, either as an experimentally controlled condition or an observational measure;

\footnotetext{
${ }^{3}$ One study was excluded as student SES was measured at the neighbourhood level
} 


\section{TEACHER RECOMMENDATION AND INEQUALITY}

5) The complete reporting of results ${ }^{4}$.

In total, 26 studies meet these criteria and are included in our final selection of teacher track recommendation research. The studies span the time frame from 2007 to 2020. In table 2 we present an overview of the included studies.

[ Table 2 about here]

\section{Empirical findings on biases in teacher track recommendation}

\subsection{Socio-economic status of students}

Overall, findings on tracking recommendations are highly consistent with respect to students' SES. Of the 19 studies that report findings on SES biases, 12 studies show that teachers provide higher tracking recommendation for students from high-SES backgrounds than for equally performing students from low-SES backgrounds ${ }^{5}$. For example, an observational study on the track recommendations for more than 11,000 French students shows that SES disparities remained after accounting for students' school marks and repeated school years (Barg, 2013). An observational study on a sample of 500 Dutch primary school teachers also found little heterogeneity in the SES bias in teacher track recommendations: all teachers gave lower track recommendations to students from lower socioeconomic backgrounds, after accounting for student performance on standardized academic tests (Timmermans et al., 2015). Using information on nine Dutch cohorts between 1995

\footnotetext{
${ }^{4}$ When this was not the case, the authors of the study were contacted. Studies were only excluded if, even upon request, the reporting of results was insufficient.

5 This includes the study by Dumont et al. (2019). They find SES disparities in teacher track recommendations in Germany after accounting for student test scores, yet these disparities disappear after also accounting for teacher-assigned grades. However, teacher biases may also affect teacher-assigned grades, such that teacher biases in tracking recommendations (partly) reflect teacher biases in grading.
} 


\section{TEACHER RECOMMENDATION AND INEQUALITY}

and 2014, these researchers also show that SES biases in teacher track recommendation have remained stable over time (Timmermans et al., 2018). Finally, two experiments in Switzerland reveal that teachers (and students playing the role of teachers) find the academic track more suitable for high-SES students whose school performance is slightly below official standards than for low-SES students with the same performance levels (Batruch et al., 2019). Similarly, keeping student performance stable, the vocational track is seen as more suitable for low- than high-SES students.

Four of the 19 studies that include SES as a predictor of teacher track recommendations find SES biases for some, but not all indicators of SES. More specifically, the observational studies by Barg (2015), Boone \& Van Houtte (2013), and Feron et al. (2016) find (some) support for SES biases when using occupational-related measures of SES, but not when using educational measures. Conversely, Caro et al. (2009) find support for SES biases when using a composite measure of SES and parental education, but not when using parental occupational status.

Three of the 19 studies find no support for SES differences in teacher track recommendations after accounting for student performance. One of them involves two experiments among primary school teachers in Luxembourg (Glock et al., 2012). The other two are observational studies, respectively on a sample of 374 grade-4 students in Southern Germany (Niklas \& Schneider, 2017) and $27316^{\text {th }}$ graders in Luxembourg (Klapproth et al., 2012). In both these studies SES is measured by parental occupational status.

\subsection{Ethnicity of students}

The findings are less consistent when considering teacher biases with respect to a student's ethnic or migration background. Of the 22 studies that report results on teacher biases by ethnic or migration background, 9 studies find (some) evidence suggesting that teachers evaluate ethnic 


\section{TEACHER RECOMMENDATION AND INEQUALITY}

minority students more negatively (Boone et al., 2018; Bruneau et al., 2020; Glock et al., 2012, 2013; Klapproth et al., 2012, 2018; Krolak-Schwerdt et al., 2018; Lüdemann \& Schwerdt, 2013; Sprietsma, 2013), 6 studies find no support for biases by students' migration or ethnic background (Boone \& Van Houtte, 2013; De Boer et al., 2010; Feron et al., 2016; Niklas \& Schneider, 2017; Timmermans et al., 2015, 2016), and another 6 studies find (some) support that students with an ethnic minority background receive higher track recommendations than their native counterparts when accounting for student performance (and SES) (Barg, 2013; Caro et al., 2009; Driessen et al., 2008; Dumont et al., 2019; Timmermans et al., 2018; Timmermans et al., 2019). Finally, there are two studies that show that teacher track recommendations are less accurate for students from migration backgrounds (Glock et al., 2015; Pit-ten Cate et al., 2016). This inaccuracy may both reflect biases in favor of, or against students' with a migration or ethnic minority background (Glock et al., 2015; Pit-ten Cate et al., 2016).

The inconsistent findings with respect to students' ethnic or migration background could partly be due to differences in research design. It seems that experimental studies typically find that teachers evaluate disadvantaged minority groups more negatively. For example, several experiments conducted on German or Luxembourgian pre- and in-service teachers find that recommendations are lower for students from ethnic minority backgrounds than for students from the ethnic majority (Glock, Krolak-Schwerdt, Klapproth, \& Böhmer, 2013; Klapproth, Kärchner, \& Glock, 2018). However, in some observational studies in which student performance is accounted for, teachers seem to evaluate students from disadvantaged minority groups more positively than students from the native majority (e.g., Barg, 2013; Driessen et al. 2008).

Findings may also be inconsistent, because teachers tend to sometimes over- and other times underestimate students from ethnic minority groups, leading to positive, negative, as well as 


\section{TEACHER RECOMMENDATION AND INEQUALITY}

null findings. An experimental study in Germany and Luxembourg indicates that track recommendations for students from ethnic minority groups are more likely to be 'inaccurate' than those for students from the ethnic majority (Glock, Krolak-Schwerdt, \& Pit-ten Cate, 2015). This implies that students from ethnic minority groups are more likely to receive higher as well as lower track recommendations than would be expected on the basis of their academic profile. Possibly, teachers overestimate some, while underestimating other ethnic minority students.

Related to this, inconsistent findings may stem from large variations across teachers in how they evaluate students from ethnic minority groups as compared to students from the native majority. A Dutch study shows that some teachers tend to give higher track recommendations to Turkish, Moroccan, and other foreign students from low socioeconomic backgrounds, while other teachers tend to give lower track recommendations to these minority groups ( Timmermans et al., 2015). These effects cancel each other out, leading to a non-significant overall effect of student migration background on teacher track recommendation.

Finally, differences in findings may also be due to differences in the year the study was conducted. In the Netherlands, ethnic biases in teacher track recommendations have changed between 1995 and 2014 (Timmermans et al., 2018). While in 1995 teachers tended to give higher track recommendations to students from ethnic minority groups than to their equally performing peers from the ethnic majority, this difference reduced over time, and eventually disappeared. The authors note that this might be due to the fact that (1) equity-related policies in the Netherlands gradually started to focus less on ethnic inequalities, and/or (2) Dutch society became less tolerant towards members of minority groups over this period. 


\section{TEACHER RECOMMENDATION AND INEQUALITY}

\section{Explaining inequality in track recommendations}

In this section, we review the sociological and psychological literature on factors that could explain why teachers provide biased recommendations. We find that three types of factors are discussed in the literature: student- and parent-related, teacher-related and institutional factors. Specifically, we review the evidence on the role of students' school-related behaviours and attitudes, parental involvement, teachers' prejudices and stereotypes and institutional policies on tracking recommendations. Whereas student- and parent-related factors in tracking recommendations have been explored, this is less the case for teacher-related and institutionalrelated factors. Hence, in these sub-sections, we also include studies that weren't included in the systematic review to shed light on the potential factors accounting for teacher biases in track recommendations

\subsection{Family and student-related factors}

\subsubsection{Student school Behaviour and Attitudes}

Whether intentionally or not, teachers base their track recommendations on students' behaviour and attitudes in class. Some scholars even argue that a teacher's expectations, judgements, or track recommendations are accurate when they are explained by either a student's performance, ability, or motivation or effort in school (e.g., De Boer et al., 2010; Timmermans et al., 2015). Of the 26 studies included in our systematic review, six studies report findings on the relation between students' school behaviour and attitudes and teacher track recommendations (De Boer et al., 2010; Driessen et al., 2008; Glock et al., 2012; Klapproth et al., 2012, 2018; KrolakSchwerdt et al., 2018; Timmermans et al., 2016). Moreover, some experimental studies account for student school behaviour and/or attitudes by including it as a stable factor in their experimental set-up (Glock et al., 2013, 2015; Pit-ten Cate et al., 2016). Finally, one study does not include 


\section{TEACHER RECOMMENDATION AND INEQUALITY}

student behavior or attitudes in its quantitative analyses of track recommendations yet sheds light on their potential impact by using (1) a questionnaire asking teachers directly how they form their track recommendations, and (2) qualitative focus groups with teachers (Boone \& van Houtte, 2013).

Most studies accounting for student behavior or attitudes include a measure for working habits, effort, or motivation, and find that this is positively related to teacher track recommendations. For example, research in Luxembourg and Germany indicates that teachers provide higher track recommendations when they have a more positive perception of a student's working behaviour (Krolak-Schwerdt et al., 2018). This relationship exists while controlling for a student's school performance (i.e., grades, and in Luxembourg also test scores) and nationality or migration background. Similarly, de Boer et al. (2010) find that when Dutch teachers evaluate students' motivation more positively, they are more likely to recommend a track that exceeds the student's shown performance and motivation (i.e., overestimate a student).

Two studies in the Netherlands (Driessen, Sleegers, \& Smit, 2008; Timmermans et al., 2016), and one study in Luxembourg (Klapproth et al., 2012), move beyond including a single indicator for students' school behaviour and attitudes. The study in Luxembourg shows that students' reliability and accuracy are positively related to teacher track recommendations, yet that there is no statistically significant relationship between students' achievement/learning motivation and teacher track recommendations (Klapproth et al., 2012). The two Dutch studies reveal that teacher track recommendations are slightly higher for students who are perceived to be more selfconfident and have better study attitudes or work habits (e.g., work hard, plan better). However, they are surprisingly lower for students who are perceived to exhibit more socially accepted behaviors (e.g., stick to the class rules) (Driessen, Sleegers, \& Smit, 2008; Timmermans et al., 


\section{TEACHER RECOMMENDATION AND INEQUALITY}

2016). Timmermans et al. (2016) find that a teacher's perceptions of a student's popularity is not predictive of teacher track recommendations. This study also shows that teachers vary in the extent to which they take into account their perceptions of a student's self-confidence, work habits and social behavior. For example, some teachers weigh self-confidence and social behaviour positively, while other teachers weigh this negatively. Moreover, teachers seem to weigh student performance by a student's behaviour and attitudes in class. More specifically, a student's performance has a stronger impact on a teacher's track recommendation when a student is perceived to have more positive work habits.

Research in Flanders suggests that some teachers consciously rely on student behaviour and attitudes when forming track recommendations: in a questionnaire 69 percent of the 390 teachers explicitly reported to base track recommendations on student attitudes and behaviours (Boone \& Van Houtte, 2013). Additional focus groups with a subset of seven teachers reveal that teachers for example take into account independence, planning capacity, responsibility, and punctuality.

Although teachers may (explicitly) rely on a school behaviours and attitudes when formulating track recommendations, research also suggests that these factors only play a minor role, and are far less important than a student's cognitive competencies (Driessen, Sleegers, \& Smit, 2008; Timmermans et al., 2016). Nevertheless, teachers' reliance on students' school behaviour and attitudes could still, in theory, contribute to socio-economic and ethnic biases in tracking recommendations.

Timmermans et al. (2016) explicitly examine whether teachers' reliance on student behaviour and attitudes explain the higher track recommendations for students from advantaged SES backgrounds, and find no support for this. Similarly, the study by Driessen et al. (2008) shows 


\section{TEACHER RECOMMENDATION AND INEQUALITY}

that the effect of parental education on teachers' track recommendation hardly changes after accounting for teachers' perceptions of student behaviour and attitudes. Relatedly, other studies that account for teachers' perceptions of student working behaviour or motivation, still find SES or ethnic gaps in teacher track recommendations after accounting for these perceptions (De Boer et al., 2010; Krolak-Schwerdt et al., 2018).

The extent to which teachers rely on a student's SES or ethnic background in their track recommendations may also depend on a student's school attitudes or behaviour. Klapproth et al. (2018) expect that the ethnic gap in a teacher's track recommendations is dependent on student absenteeism. Ethnic minority students who show high absence rates may confirm the stereotype of ethnic minority students as poor academic performers, leading to an activation of the ethnic stereotype in teachers, and higher ethnic discrepancies in teacher track recommendations. To test this idea, the authors conduct a vignette experiment among 95 preservice teachers in Germany. In the vignette experiments respondents are asked whether or not they are in favour of placing a hypothetical male student in the highest secondary school track. The GPA, ethnicity (i.e., Turkish or German), and absence rates of the hypothetical student are experimentally manipulated. The authors do not find clear support for their hypothesis. Overall, students with a higher GPA, with a German background, and with low absence rates are more likely to be assigned to the highest track. In line with the hypothesis, higher absence rates are related to a greater reduction in the likelihood for a high track-recommendation for Turkish students with a high GPA than for German students with a high GPA. However, among students with a low or medium GPA, high absence rates only decrease the probability to be recommended to a high track for German, but not for Turkish students.

\subsubsection{Family-related factors}




\section{TEACHER RECOMMENDATION AND INEQUALITY}

Eight of the 26 studies that are included in the systematic review report findings on how characteristics of the home environment, such as parental school support and aspirations, are related to teacher track recommendations (Barg, 2013, 2015; De Boer et al., 2010; Driessen et al., 2008; Dumont et al., 2019; Klapproth et al., 2018; Krolak-Schwerdt et al., 2018; Niklas \& Schneider, 2017). Moreover, some experimental studies account for characteristics of the home environment by including it as a stable factor in the experimental set-up (Glock et al., 2015; Pitten Cate et al., 2016).

Various studies show that parental support and school involvement - or a teacher's perception thereof - are related to higher track recommendations. For example, a study in France shows a positive relationship between parents' involvement in parent associations and teacher track recommendations (Barg, 2013). Research among German primary school teachers indicates that teacher track recommendations are higher when teachers perceive parents to provide more support in problems that occur in school (Krolak-Schwerdt et al., 2018). Similarly, a Dutch study indicates that teachers provide higher track recommendations to students who live in homes that teachers perceive to be supportive (e.g., homes in which learning and curiosity are stimulated) (Driessen et al., 2008).

Teachers generally have more positive perceptions of the involvement of parents from higher SES backgrounds (Bakker et al., 2007). Since these perceptions seem to positively impact teacher track recommendations, social inequality in tracking recommendations could be explained by social disparities in teachers' perceptions of parental school involvement. However, Driessen et al. (2008) show that the positive relationship between parental SES and teacher tracking recommendation in the Netherlands hardly changes after accounting for teachers' perception of the home environment. 


\section{TEACHER RECOMMENDATION AND INEQUALITY}

Parents from advantaged socioeconomic backgrounds may also be more likely to question the tracking decisions of the school or to (successfully) exert (implicit) 'pressure' on track recommendations. Studies find that parental aspirations and preferences for their child's educational attainment are positively related to teacher track recommendations (De Boer et al., 2010; Dumont et al., 2019; Klapproth et al., 2012). However, de Boer et al (2010) still find SES biases in teacher track recommendations after accounting for parental aspirations ${ }^{6}$. Findings by Dumont et al. (2019) do suggest that the relatively high aspirations among parents with a migration background may partly explain the higher track recommendations for students with a migration background. That is, after accounting for parental aspirations, Dumont et al. (2019) do not find a positive effect anymore of being a student with a migration background on teacher track recommendations.

Research among 11,000 students in France shows that SES differences in teacher track recommendations are heavily reduced (or disappear) when accounting for families' school track requests(Barg, 2013, 2015). Barg (2013) suggests that schools may expect that (upper) middle class parents will object to relatively 'low' track recommendations, and try to avoid such objections by giving higher track recommendations to students from (upper) middle class

\footnotetext{
${ }^{6}$ The other two studies do not reveal whether SES differences in parental aspirations can account for SES biases in teacher track recommendations. In the study by Dumont et al (2019) SES disparities in teacher track recommendations already disappear after accounting for teacherassigned grades, and before parental aspirations are added to the model. In the study by Klapproth et al (2012) student SES and migration background are not included in a model that includes parental aspirations.
} 


\section{TEACHER RECOMMENDATION AND INEQUALITY}

backgrounds (Barg, 2013, 2015). It should be noted that, in France, schools explicitly take into account parental wishes in their track recommendations (Barg, 2013). In a first stage, parents are asked to request a track for their child; subsequently, the school staff recommends a track; and, finally, the family can reject the recommendation.

In sum, findings are mixed with respect to the role of family-related factors in inequality in teacher tracking recommendations. On the one hand, teachers perceive parental school involvement to be higher for students from more advantaged SES backgrounds (Bakker et al., 2007), and research shows that such perceptions are in turn related to higher track recommendations. However, SES disparities in teacher track recommendations remain after accounting for teacher perceptions of parental support or involvement, indicating that this cannot (fully) explain SES inequality in teacher track recommendations. Some studies do indicate that parents from advantaged socioeconomic backgrounds exert more implicit pressure on teachers, and/or are more likely to requests for higher tracks, leading to social inequality in track recommendations. However, current findings are still inconclusive.

\subsection{Teachers' stereotypes and prejudicial attitudes}

Psychological research has often studied teacher stereotypes and prejudicial attitudes as an outcome variable, thereby assuming that these could explain inequality in educational outcomes. However, few studies have directly tested this link. Notably, only two studies that are included in our systematic literature review shed light on the extent to which inequality in tracking recommendation depend on teachers' prejudicial attitudes. In the first one, 88 German teachers were asked to grade 10 essays supposedly produced by German or Turkish students, and to fill in feeling thermometers about 12 social groups, including Germans and Turks. Based on the essay, the teachers were then asked to formulate school track recommendations. By including essay and 


\section{TEACHER RECOMMENDATION AND INEQUALITY}

teacher fixed effects in the analyses, the author account for essay quality and teacher severity (Sprietsma, 2013). Whereas, the author finds support for inequality in grading (10\% of a standard deviation in test scores worse for Turkish students around the passing grade) and in track recommendation ( $11 \%$ lower probability for Turkish students to receive a recommendation for the higher track with the same essay) and more positive attitudes towards Germans than Turks $(8,5$ attitude gap), neither teachers' personal characteristics (age, gender, etc.) nor prejudicial attitudes accounted for the bias in grades or recommendations.

The second study concerns a study among 161 Hungarian preservice teachers who were asked to respond to questions about blatant and subtle dehumanization and to fill out feeling thermometers about Roma Hungarians (Bruneau et al., 2020). Six weeks later, they were contacted again supposedly for another study about track recommendations. Teachers were asked to assess how suitable 22 different students were for the low, middle and high school track on a scale ranging from 0-100. Student profiles included student names (either typically Roma or non-Roma) and competence and subject test scores. They found that Roma students were perceived as (marginally) better suited for the low track and (marginally) less well suited for the high track, as compared to non-Roma students. The authors then created a discrimination score by averaging the tendency to favor placing Roma over non-Roma in the low track with the tendency to favor placing non-Roma over Roma in the high track, and regressed this discrimination score on teachers' blatant dehumanization, subtle dehumanization, and prejudice. Only blatant dehumanization was found to be a significant predictor of discrimination. However, the authors note that these results may not necessarily be generalizable to other minority groups and/or countries.

\subsubsection{Implicit stereotypes and prejudicial attitudes and inequality in student outcomes.}




\section{TEACHER RECOMMENDATION AND INEQUALITY}

As only two studies included in our systematic review shed light on the role of teacher stereotypes and prejudicial attitudes in inequality in teacher track recommendations, we also briefly review research on the link between teachers' implicit and explicit stereotypes and prejudicial attitudes and inequality in other student outcomes.

A recent meta-analysis conducted on teachers' implicit associations finds that teachers hold implicit preferences for non-marginalized group (Pit-ten Cate \& Glock, 2019). They report that the effect size of this preference is medium $(d=0.56)$. Two recent reviews found that, in some studies, those implicit or explicit preferences are related to teachers' classroom behaviours or unequal student outcomes Denessen, Hornstra, van de Bergh, \& Bijlstra, in press; Turetsky, Sinclair, Starck, \& Shleton, 2021). However, most studies (11 out of 17 for implicit measures and 8 out of 11 for explicit measures) present mixed findings or no effect at all (Denessen, Hornstra, van de Bergh, \& Bijlstra, in press).

Among the studies that find a positive effect, a study in New Zealand finds that some students performed better when a teachers' implicit prejudice favours their ethnicity (Peterson, 2016). Moreover, a Dutch study shows that teachers' implicit prejudiced attitudes are related to a difference in standardized mathematic and text comprehension test scores (Van den Bergh et al., 2010). Results of a mediation model indicates that teachers' implicit attitudes are related to ethnic differences in student's achievement scores through ethnic differences in teachers' expectations. In the U.S., test scores between Black and White students are larger in counties where teachers hold more implicit and explicit anti-Black/pro-White bias (Chin et al., 2020).

A recent study tests the effect of teachers' implicit attitudes towards immigrants on their discriminatory behavior much more directly with a large sample of Italian teachers $(N=533)$ and their $8^{\text {th }}$-grade students $(N=5$ '141) (Alesina, Carlana, La Ferrara, \& Pinotti, 2018). Math and 


\section{TEACHER RECOMMENDATION AND INEQUALITY}

literature teachers were administered an IAT test and an explicit questionnaire about their beliefs about immigrants. Results show a marginal effect $(p=.085)$ of implicit attitudes on grades for math teachers, and no effect for literature teachers: Math teachers with stronger implicit stereotypes against immigrants give immigrant students lower grades, holding constant students’ math ability (measured by standardized test scores). The size of the effect however is very small: one standard deviation increase in teachers' IAT score is associated with a 0.033 decrease in immigrants' grades in math on a scale from 3 to 10 . To test whether revealing IAT scores to teachers affects subsequent behavior, the researchers manipulated the time at which this feedback was provided to teachers. The results were sent by e-mail either before or after teachers graded their students. To avoid experimenter demander effects, teachers were not informed that the researchers could access final semester grades. Findings show that when teachers receive the feedback before grading, immigrant students' grades increases about 0.5 for math and 0.4 for literature, while grades for natives decrease by 0.2 points in both subjects. This "treatment" only affects teachers with positive explicit beliefs about immigrants.

At first glance, these results appear promising to effectively reduce biases in teacher behavior. However, it could be that teachers who were likely to act upon their bias (i.e., with positive explicit beliefs about immigrants) proceed to positively discriminate immigrant students. Although the design and scale of this study set an important example for future research to reliably test the effect of stereotypes on teacher behavior in classrooms settings, the results do not provide convincing support for the hypothesis that implicit measures meaningfully predict biased behavior, or that revealing implicit stereotypes is effective at reducing them.

\subsubsection{Teacher stereotypes and prejudicial attitudes: Methodological considerations}




\section{TEACHER RECOMMENDATION AND INEQUALITY}

While more and more research focuses on the impact of teacher prejudices on inequality in students' educational outcomes, this literature still suffers from methodological shortcomings. Many studies are conducted on small samples of (pre-service) teachers (Denessen, Hornstra, van de Bergh, \& Bijlstra, in press; Turetsky, Sinclair, Starck, \& Shleton, 2021). Additionally, there are inherent social desirability issues when examining the relationship between explicit prejudice, stereotypes, and track recommendations in classrooms. It could be for this reason that the few studies that do report a link between negative attitudes and students' outcomes or teachers' behaviour find this effect only with very stigmatized groups or for implicit stereotypes. But there is an ongoing debate about the interpretation and reliability of measures of implicit stereotypes. The IAT has been heavily criticized for having low psychometrics value, including low predictive value of discriminatory behaviour (1-2-\% of variance explained; Carlsson \& Agerström, 2016; Forscher et al.; 2018) and low test-retest reliability ( $\mathrm{r}=0.4-0.6)$ (Blanton et al., 2009; Gawronsky, Morrison, Phills, \& Galdi, 2017; Greenwald, Banaji, \& Nosek, 2015; Oswald et al., 2013). Many researchers contend that IAT measures are too noisy to reliably be diagnostic of implicit bias and IAT scores should be interpreted with caution (Greenwald, Banaji, \& Nosek, 2015; Oswald, Mitchell, Blanton, Jaccard, \& Tetlock, 2015).

In sum, there are very few studies that study the link between teacher biases and inequality in tracking. There is, however, a growing interest in linking teacher biases to other student educational outcomes. This research area does show some promising results, but most studies present either mixed findings and/or have methodological shortcomings. Many of these shortcomings may be due to the difficulty of accessing large numbers of teachers and/or designing a study that avoids (or limits) social desirability biases in responses and using implicit measures (whose interpretation are still debated). In other words, more robust research may be 


\section{TEACHER RECOMMENDATION AND INEQUALITY}

needed before confidently attesting that teacher biases contribute to inequality in tracking decisions.

\subsection{Institutional features}

Despite the theoretical accounts suggesting that schools and educational systems play a part in the reproduction of social inequalities, the bulk of the literature only sheds light on potential individual-level mechanisms contributing to inequality in tracking recommendations, such as student or family-related characteristics. According to the theoretical perspectives highlighting the importance of schools and educational systems, educational institutions are cultural contexts that shape the way in which teachers behave, and that contribute to the (re)production of social inequalities (Adams et al., 2005; Geven et al., 2021; Stephens, et al., 2012; Thornton \& Ocasio, 2008).

Only two studies included in our systematic review pay attention to the potential role of institutional features in inequality in tracking recommendations. First, a study by Glock et al. (2012) examined the role of accountability induced by the institutional context on inequality in teacher tracking recommendations. Teachers were randomly assigned to three different experimental conditions. In the first condition, teachers had sole responsibility for their tracking

decisions and decisions had a large impact on the future educational and occupational careers of students. In the second condition, teachers had to advice a colleague on his/her track recommendations, without further commitment. In the third condition, teachers had to prepare tracking decisions for a council, and were informed that the final tracking decision would be made by the council. This last condition corresponds to the actual tracking procedure in Luxembourg. In one of the two experiments, the researchers found that student nationality only impacted teacher track recommendations in the second condition, and that teachers also felt less 


\section{TEACHER RECOMMENDATION AND INEQUALITY}

accountable for their tracking decision in this condition than in the first and last condition. However, these findings were not replicated in a second experiment in which teachers were asked to think out loud during the experiment.

Second, Batruch et al. (2019) tested whether directing evaluators either towards the 'selective function' (of classifying students) or the 'educational function' (of helping all students) of schooling would impact social inequality in tracking decision. One of their experiments tested whether manipulating a target student's socioeconomic status as well as the school's function resulted in differences in the tracking decisions of student participants playing the role of teachers $(N=160)$. The results indicated that for the higher track, the high-SES pupil was considered the most suitable in the selection condition, followed by the high-SES pupil in the educational condition, next the low-SES pupil in the educational condition, and finally the low-SES pupil in the selection condition. The order was reversed with respect to suitability for the lower track. These findings imply that SES inequality in teacher recommendations is larger when the educational selection function is salient than when the educational function is salient.

The findings of Batruch et al. (2019) are in line with findings from an earlier study on teachers' grading of students. In this study, 455 students playing the role of teachers were asked to assess a dictation test which was supposedly produced by a low or a high-SES student (Autin, Batruch, \& Butera, 2018, experiment 3). To assess the test, participants had to use either a selective assessment method (i.e., grading) or an educational assessment method (i.e., providing comments). When participants used the selective assessment method, they found more mistakes in the low-SES condition than in the high-SES condition for the same test. This difference was not found when participants used an educational assessment method. 


\section{TEACHER RECOMMENDATION AND INEQUALITY}

Both the studies by Batruch et al. (2019) and Autin et al. (2018, experiment 3) suggest that institutional selection tools such as tracking may induce SES inequalities in the evaluations of teachers. These findings highlight that contexts in which evaluators are encouraged to focus on selecting students may enhance or cause biases.

As only a couple of studies that are included in our review study examine the potential role of the institutional context in inequality in tracking recommendations, we will also discuss findings of studies that are not included in our systematic review but that do shed light on how educational institutions may induce/inhibit biased recommendations.

\subsubsection{Track Allocation Institutions.}

Several studies have examined the role of track allocation institutions in inequality in tracking or streaming or other educational outcomes. Most of these studies focus on the role of standardized testing in track allocation. Overall, empirical findings on the relationship between standardized testing and inequality in educational outcomes are mixed (Bol et al., 2014; CPB 2020; Wössmann et al., 2009; Horn, 2009; van Leest et al. 2020; Luyten and Bosker 2004). A few of these studies explicitly focus on inequality in teacher tracking recommendations (CPB 2020; van Leest et al. 2020; Luyten and Bosker 2004). Using data on more than 5000 children in over 400 schools in the Netherlands in the school year of 2000-2001, Luyten and Bosker (2004) find that in schools where a standardized test is administered in the final year of primary school ${ }^{7}$, the SES difference in the recommendations is smaller.

\footnotetext{
${ }^{7}$ The Dutch law changed such that schools are now required to participate in a
} standardized tests in the final year of primary school. 


\section{TEACHER RECOMMENDATION AND INEQUALITY}

A more recent Dutch study compared the track recommendations for cohorts of students where final-year standardized test scores were available to teachers prior to formulating their track recommendation, to teachers' track recommendations for cohorts of students where recommendations were formulated prior to receiving students' final-year standardized test scores. No difference in SES inequality in track recommendations was found between the two cohorts. This suggests that final-year standardized tests do not reduce inequality in teacher track recommendation. It should be noted that student SES was based on a proxy measuring the average SES of the neighborhood in which a student lived.

Other Dutch research indicates that standardized testing does reduce SES inequality in track recommendations (CPB 2020). Under the current law, Dutch teachers have to formulate a track recommendation before students make a final standardized tests (CPB 2019). When students score higher on the test, they are eligible for an upward adjustment in their track recommendation. Research shows that upward adjustments occur more frequently among students from disadvantaged socio-economic backgrounds (CPB 2020), as this group is more often eligible for an upward adjustment (i.e., their test scores more often exceed the teacher's track recommendation) (CPB 2019).

Relatedly, a natural experiment among third graders in a school district in the United States suggests that standardized examinations reduce educational inequality in gifted program placement (Card \& Giuliano, 2016). In this district, non-disadvantaged students with an IQ score of 130 points or higher, and English language learners and free-or-reduced price lunch receivers with an IQ score of 116 points or higher were eligible for the gifted program. To receive an IQ test, students had to be directed to a psychologist by their teacher or parents. Despite the lower IQ requirements for disadvantaged students, white and higher income students were 


\section{TEACHER RECOMMENDATION AND INEQUALITY}

overrepresented in the gifted program. Hence, in 2005, the district decided to subject all students to a standardized ability test. Students whose test score surpassed the threshold were directed to a psychologist for an IQ test. The introduction of the universal test substantially increased the number of third grade students in gifted programs, and this number dropped again as soon as the test was dropped. Moreover, the increase in the number of gifted students after the introduction of the test was mainly due to an increase in the proportion of disadvantaged students receiving a 'gifted' status (i.e., poor students, racial minorities, and students with non-English speaking parents).

Besides research addressing how the use of standardized testing in track allocations relates to educational inequality, Thys (2018) examines how a school's explicit attention to track allocation is related to inequality in teacher track recommendations in 32 schools in two cities in Flanders (Antwerp and Ghent). To measure the attention paid to the track allocation procedures in school, teachers were asked about the opportunities their school provided to professionalize and cooperate with respect to track allocations, and the clarity of the school's vision with respect to ability tracking. Results indicate that students from advantaged socio-economic backgrounds were more likely to receive a recommendation for the academic track, especially in schools in which teachers feel that more explicit attention is paid to the track allocation procedure. This difference between schools loses statistical significance after accounting for the impact of teachers' perception of students' study attitudes and parental support. This suggests that in schools in which explicit attention is paid to track allocation procedures, teachers are more likely to also take into account student characteristics other than academic performance. Since some of these characteristics are correlated with SES, SES differences in teacher track recommendations become larger. 


\section{TEACHER RECOMMENDATION AND INEQUALITY}

Finally, in a recent study, Geven et al (2021) use a vignette experiment to compare teacher expectations across three different contexts - New York City, Oslo, and Amsterdam. These contexts differ with respect to crucial institutional features, including tracking institutions. The findings reveal that teachers in different contexts rely on the same student traits to form expectations yet weigh these traits differently. In Amsterdam - a context characterized by early between-school tracking and intense standardized testing to assess student ability - teachers rely more on academic performance to form expectations. In Oslo, teachers base their expectations more on student SES, seemingly because they make more inferences about student performance on the basis of student SES. NYC teachers hardly make inferences about student performance on the basis of student SES. The authors argue that making inferences about student performance on the basis of student SES may lead to inaccurate expectations for individual students. However, the fact that NYC teachers hardly make such inferences may also reflect a blindness to actual educational inequalities in the country.

\section{Future Directions}

Research suggest that teacher stereotypes and prejudices, student or family-related factors are unable to fully mediate (or explain) inequality in tracking recommendations. Institutional characteristics are possible moderators that may increase/reduce inequality in educational outcomes, yet research is still scarce. We argue that future research may especially want to focus on institutional characteristics, as, up to now, there are not yet prejudice reduction methods with long-term effects in real-world settings (Fitzgerald et al., 2019). That is, no current method can consistently decrease implicit biases or biased behaviour in the long-term (Forscher et al., 2018) and most studies only show modest short-term effects in laboratory settings (Paluck \& Green, 2009; Paluck et al., 2020). 


\section{TEACHER RECOMMENDATION AND INEQUALITY}

If researchers are interested in factors that could be useful for educational institutions, it is important to examine low-cost structural factors that can be implemented at the institutional level. A few recent psychological studies show that certain contextual features can impact the expression of biases. This work has not been conducted in educational settings, yet could be promising for future research in educational settings. In the next section we discuss these studies.

\subsection{Research on the contextual influences on the expression of bias}

Recent experiments highlight that specific decision-making contexts can impact the extent to which participants discriminate in a social judgement task (Axt \& Lai, in press; Axt, Casola, \& Nosek, 2018; Lai \& Banaji, 2020). Seven pre-registered studies $\left(N>7^{\prime} 000\right)$ revealed that asking participants to avoid a potential bias for one social category reduced the bias for that category in an academic judgement task (i.e. selecting honor society applicants based on academic credentials) (Axt, Casola, \& Nosek, 2019). However, it did not reduce biases in other social categories, and the strategy proved ineffective when statements included more than one social category. In eight other studies $\left(N>7^{\prime} 000\right)$, the authors replicated the finding that warning participants for biases reduced those biases. Moreover, they found that not revealing applicant's social category (i.e. blinding application) was an effective method to reduce bias. Other situational techniques were also tested, (e.g. manipulating time constraints or motivation) which did reduce the number of errors that participants made, and therefore partly the number of biases, yet it did not reduce the share of biases in people's errors (Axt \& Lai, 2019). These findings suggests that inequality in track recommendations may be reduced by involving third-party teachers who formulate tracking recommendations on the basis of anonymized students' records.

Uhlmann and Cohen (2005) also provide an interesting demonstration of how bias can manifest in specific contexts. They asked participants to select one of two candidates, Michael or Michelle, for promotion to the position of police chief. Michael and Michelle had identical 


\section{TEACHER RECOMMENDATION AND INEQUALITY}

dossiers, except that one candidate was known for his/her practical knowledge (streetsmart), while the other was known for being formally educated (book smart). The gender of the candidate possessing the competence was reversed in the other condition. After reviewing the candidates, participants were more likely to select Michael rather than Michelle. When asked why, participants mentioned either the importance of formal training or being streetsmart for the job depending in which condition Michael was. This shows that biases can encourage individuals to change the importance of certain criteria after the fact. In a second study, participants were asked to report on what qualities were important to being a police chief before selecting a candidate. When the criteria were selected before, the bias disappeared. This finding suggests that constraining decision-makers to more objective criteria can powerfully reduce bias (Lai \& Banaji, 2020). In the context of educational institutions, this could mean for instance relying on standardized competency indicators or institute predefined objective criteria for track recommendations (c.f., Vanlommel \& Schildkamp, 2018).

\section{Conclusion}

In this paper, we conducted a systematic and integrative review to answer two main questions: 1) Are teacher recommendations biased against students from disadvantaged socioeconomic and/or ethnic backgrounds? 2) Which factors account for social and ethnic inequalities in teacher tracking recommendations? To answer the first question, we conducted a systematic review of 26 recent articles (from 2000 onward) and concluded that teacher recommendations are in fact biased against students from disadvantaged socio-economic background, even when performance is controlled for. Evidence with respect to ethnic biases in teacher track recommendations is more mixed. 


\section{TEACHER RECOMMENDATION AND INEQUALITY}

To answer the second question, we reviewed the literature on factors that could explain why teachers provide biased recommendations. We found support for the idea that student and family factors affect teacher track recommendations, yet we found little support for the idea that these factors (fully) explain inequality in teachers' track recommendation. In other words, these factors do not appear to mediate the relationship between students' socioeconomic or ethnic background and teacher track recommendations. While there is some preliminary evidence suggesting that teachers' biases can affect student educational outcomes, more robust research is needed. We suggest that research on the impact of institutional characteristics on inequality in education shows promise not only for making scientific contributions (i.e. how institutions can shape individual behavior), but also for finding pathways to reduce bias in tracking as well. Indeed, it is likely easier to change policies and institutions than to change students home environments or teachers long-held beliefs. Finally, we suggest some ideas for future research. Notably, we propose that the research field on institutional/contextual factors on decision-making processes could offer potentially interesting avenues for research on inequality in tracking recommendations, as it proposes ideas that could easily be adapted to real-world educational settings. If they are effective, they could conveniently be implemented at the institutional level.

While various studies have now established that there are inequalities in tracking recommendations, studies that tackle the underlying mechanisms and potential moderators of this inequality are still scarce (see for example Timmermans et al. 2016 for an exception). Research on inequality in tracking seems to especially pay little attention to the broader institutional context in which inequalities come about, and thereby could give the impressions that reducing inequality can only be dealt with at the individual (teacher) level. We suggest that unequal, or even biased, tracking decision can also be the product of the way in which educational institutions operate and 


\section{TEACHER RECOMMENDATION AND INEQUALITY}

are structured. Social psychological research has too often constructed its theoretical models in a societal and institutional vacuum and may therefore have been irrelevant to policy-makers (Pettigrew, 2001). If educational psychological research hopes to substantially contribute to policies, then the field should consider broadening their understanding of inequality in education by incorporating the societal, institutional and situational conditions that shape how actors think and behave. 


\section{TEACHER RECOMMENDATION AND INEQUALITY}

\section{References}

Adams, G., Biernat, M., Branscombe, N. R., Crandall, C. S., \& Wrightsman, L. S. (2008).

Beyond prejudice: Toward a sociocultural psychology of racism and oppression. In G.

Adams, M. Biernat, N. R. Branscombe, C. S. Crandall, \& L. S. Wrightsman (Eds.).

Commemorating Brown: The social psychology of racism and discrimination (pp. 215- 246).

Washington, DC: American Psychological Association.

Alesina, A., Carlana, M., Ferrara, E. L., \& Pinotti, P. (2018), "Revealing stereotypes: Evidence from immigrants in schools", NBER Working Paper 25333.

Axt, J. R., Casola, G., \& Nosek, B. A. (2019). Reducing social judgment biases may require identifying the potential source of bias. Personality and Social Psychology Bulletin. Advance online publication.

Axt, J. R., \& Lai, C. K. (2019). Reducing discrimination: A bias versus noise perspective. Journal of Personality and Social Psychology, 117(1), 26.

Bakker, J., Denessen, E., \& Brus-Laeven, M. (2007). Socio-economic background, parental involvement and teacher perceptions of these in relation to pupil achievement. Educational Studies, 33(2), 177-192.

Barg, K. (2013). The influence of students' social background and parental involvement on teachers' school track choices: Reasons and consequences. European Sociological Review, $29(3), 565-579$.

Barg, K. (2015). Educational choice and cultural capital: Examining social stratification within an institutionalized dialogue between family and school. Sociology, 49(6), 1113-1132. 


\section{TEACHER RECOMMENDATION AND INEQUALITY}

Batruch, A., Autin, F., Bataillard, F., \& Butera, F. (2019). School selection and the social class divide: How tracking contributes to the reproduction of inequalities. Personality and Social Psychology Bulletin, 45(3), 477-490.

De Boer, H., Bosker, R. J., \& van der Werf, M. P. (2010). Sustainability of teacher expectation bias effects on long-term student performance. Journal of Educational Psychology, 102(1), 168.

Van den Bergh, L., Denessen, E., Hornstra, L., Voeten, M., \& Holland, R. W. (2010). The implicit prejudiced attitudes of teachers: Relations to teacher expectations and the ethnic achievement gap. American Educational Research Journal, 47(2), 497-527.

Blanton, H., Jaccard, J., Klick, J., Mellers, B., Mitchell, G., \& Tetlock, P. E. (2009). Strong claims and weak evidence: Reassessing the predictive validity of the IAT. Journal of Applied Psychology, 94(3), 567.

Bol, Thijs, Jacqueline Witschge, Herman G. Van de Werfhorst, and Jaap Dronkers. 2014. “Curricular Tracking and Central Examinations: Counterbalancing the Impact of Social Background on Student Achievement in 36 Countries.” Social Forces 92(4):1545-72.

Boone, S., Thys, S., Van Avermaet, P., \& Van Houtte, M. (2018). Class composition as a frame of reference for teachers? The influence of class context on teacher recommendations. British Educational Research Journal, 44(2), 274-293.

Boone, S., \& Van Houtte, M. (2013). Why are teacher recommendations at the transition from primary to secondary education socially biased? A mixed-methods research. British Journal of Sociology of Education, 34(1), 20-38. 


\section{TEACHER RECOMMENDATION AND INEQUALITY}

Bruneau, Emile, Hanna Szekeres, Nour Kteily, Linda R. Tropp, and Anna Kende. 2020. "Beyond Dislike: Blatant Dehumanization Predicts Teacher Discrimination.” Group Processes \& Intergroup Relations 23(4):560-77.

Brunello, G., \& Checchi, D. (2007). Does school tracking affect equality of opportunity? New international evidence. Economic Policy, 22(52), 782-861.

Card, David, and Laura Giuliano. 2016. "Universal Screening Increases the Representation of Low-Income and Minority Students in Gifted Education." Proceedings of the National Academy of Sciences 113(48):13678-83.

Carlsson, R., \& Agerström, J. (2016). A closer look at the discrimination outcomes in the IAT literature. Scandinavian Journal of Psychology, 57(4), 278-287.

Caro, D. H., Lenkeit, J., Lehmann, R., \& Schwippert, K. (2009). The role of academic achievement growth in school track recommendations. Studies in Educational Evaluation, 35(4), 183-192.

Chin, M. J., Quinn, D. M., Dhaliwal, T. K., \& Lovison, V. S. (2020). Bias in the air: A nationwide exploration of teachers' implicit racial attitudes, aggregate bias, and student outcomes. Educational Researcher, 49(8), 566-578.

Chmielewski, A. K. (2014). An international comparison of achievement inequality in withinand between-school tracking systems. American Journal of Education, 120(3), 293-324.

CPB. 2019. De Waarde van Eindtoetsen in Het Primair Onderwijs. CPB.

CPB. 2020. Schrappen Eindtoets Groep 8 Kan Ongelijkheid Vergroten. CPB.

Denessen, E., Hornstra, L., van den Bergh, L., \& Bijlstra, G. (2020). Implicit measures of teachers' attitudes and stereotypes, and their effects on teacher practice and student outcomes: A review. Learning and Instruction, 101437. 


\section{TEACHER RECOMMENDATION AND INEQUALITY}

Driessen, G. (2015). Teacher ethnicity, student ethnicity, and student outcomes. Intercultural Education, 26(3), 179-191.

Driessen, G., Sleegers, P., \& Smit, F. (2008). The transition from primary to secondary education: Meritocracy and ethnicity. European Sociological Review, 24(4), 527-542.

Dumont, H., Klinge, D., \& Maaz, K. (2019). The Many (Subtle) Ways Parents Game the System: Mixed-method Evidence on the Transition into Secondary-school Tracks in Germany. Sociology of Education, 92(2), 199-228.

Esser, H. (2016). The model of ability tracking-theoretical expectations and empirical findings on how educational systems impact on educational success and inequality. In Blossfeld, Hans-Peter; Buchholz, Sandra; Skopek, Jan; Triventi, Moris (Ed.), Models of Secondary Education and Social Inequality: An International Comparison (pp. 25-44). Edward Elgar Publishing Limited.

Feron, E., Schils, T., \& Ter Weel, B. (2016). Does the teacher beat the test? The Value of the Teacher's Assessment in Predicting Student Ability. De Economist, 164(4), 391-418.

FitzGerald, C., Martin, A., Berner, D., \& Hurst, S. (2019). Interventions designed to reduce implicit prejudices and implicit stereotypes in real world contexts: a systematic review. BMC psychology, 7(1), 1-12.

Forscher, P. S., Lai, C. K., Axt, J. R., Ebersole, C. R., Herman, M., Devine, P. G., \& Nosek, B. A. (2019). A meta-analysis of procedures to change implicit measures. Journal of Personality and Social Psychology, 117(3), 522-559. http://dx.doi.org/10.1037/pspa0000160

Fox, L. (2015). Seeing potential: The effects of student-teacher demographic congruence on teacher expectations and recommendations. AERA Open, 2(1), 2332858415623758. 


\section{TEACHER RECOMMENDATION AND INEQUALITY}

Gamoran, A. (2009). Tracking and inequality: New directions for research and practice (pp. 231-246). Routledge.

Gawronski, B., Morrison, M., Phills, C. E., \& Galdi, S. (2017). Temporal stability of implicit and explicit measures: A longitudinal analysis. Personality and Social Psychology Bulletin, 43(3), 300-312.

Geven, Sara, Øyvind N. Wiborg, Rachel E. Fish, and Herman G. van de Werfhorst. 2021. "How Teachers Form Educational Expectations for Students: A Comparative Factorial Survey Experiment in Three Institutional Contexts.” Social Science Research 102599.

Glock, S., Krolak-Schwerdt, S., Klapproth, F., \& Böhmer, M. (2012). Improving teachers' judgments: Accountability affects teachers' tracking decisions. International Journal of Technology and Inclusive Education, 1, 89-98.

Glock, S., Krolak-Schwerdt, S., Klapproth, F., \& Böhmer, M. (2013). Beyond judgment bias: How students' ethnicity and academic profile consistency influence teachers' tracking judgments. Social Psychology of Education, 16(4), 555-573.

Glock, S., Krolak-Schwerdt, S., \& Pit-ten Cate, I. M. (2015). Are school placement recommendations accurate? The effect of students' ethnicity on teachers' judgments and recognition memory. European Journal of Psychology of Education, 30(2), 169-188.

Greenwald, A. G., Banaji, M. R., \& Nosek, B. A. (2015). Statistically small effects of the Implicit Association Test can have societally large effects. Journal of Personality and Social Psychology, 106, 553-561.

Horn, Daniel. 2009. “Age of Selection Counts: A Cross-Country Analysis of Educational Institutions." Educational Research and Evaluation 15(4):343-66. 


\section{TEACHER RECOMMENDATION AND INEQUALITY}

Klapproth, F., Glock, S., Böhmer, M., Krolak-Schwerdt, S., \& Martin, R. (2012). School placement decisions in Luxembourg: Do teachers meet the Education Ministry's standards? Literacy Information and Computer Education Journal, 1, 765-771.

Klapproth, F., Kärchner, H., \& Glock, S. (2018). Do Students’ Religion and School Absences Moderate the Effect of Ethnic Stereotypes on School-Placement Recommendations? The Journal of Experimental Education, 86(2), 173-194.

Kloosterman, R., Ruiter, S., De Graaf, P. M., \& Kraaykamp, G. (2009). Parental education, children's performance and the transition to higher secondary education: Trends in primary and secondary effects over five Dutch school cohorts (1965-99). The British Journal of Sociology, 60(2), 377-398.

Krolak-Schwerdt, S., Hörstermann, T., Glock, S., \& Böhmer, I. (2018). Teachers’ Assessments of Students' Achievements: The Ecological Validity of Studies Using Case Vignettes. The Journal of Experimental Education, 86(4), 515-529. https://doi.org/10.1080/00220973.2017.1370686

Lai, C. K., \& Banaji, M. R.(2020). The psychology of implicit intergroup bias and the prospect of change. In D. Allen \& R. Somanathan (Eds.), Difference without Domination: Pursuing Justice in Diverse Democracies.Chicago, IL: University of Chicago Press.

Van Leest, Anne, Lisette Hornstra, Jan van Tartwijk, and Janneke van de Pol. 2020. “Test-or Judgement-Based School Track Recommendations: Equal Opportunities for Students with Different Socio-Economic Backgrounds?” British Journal of Educational Psychology.

Lüdemann, E., \& Schwerdt, G. (2013). Migration background and educational tracking. Journal of Population Economics, 26(2), 455-481. 


\section{TEACHER RECOMMENDATION AND INEQUALITY}

Luyten, H., and R. J. Bosker. 2004. “Hoe Meritocratisch Zijn Schooladviezen?” Pedagogische Studiën 81(2):89-103.

Niklas, F., \& Schneider, W. (2017). Home learning environment and development of child competencies from kindergarten until the end of elementary school. Contemporary Educational Psychology, 49, 263-274.

Organisation for Economic Co-operation and Development. (2011). Equity and quality in education-supporting disadvantaged students and schools. Paris, France.

Oswald, F. L., Mitchell, G., Blanton, H., Jaccard, J., \& Tetlock, P. E. (2013). Predicting ethnic and racial discrimination: A meta-analysis of IAT criterion studies. Journal of Personality and Social Psychology, 105(2), 171-192.

Oswald, F. L., Mitchell, G., Blanton, H., Jaccard, J., \& Tetlock, P. E. (2015). Using the IAT to predict ethnic and racial discrimination: Small effect sizes of unknown societal significance. Journal of Personality and Social Psychology, 108, 562-571.

Paluck, E. L., \& Green, D. P. (2009). Prejudice reduction: What works? A review and assessment of research and practice. Annual review of psychology, 60, 339-367.

Paluck, E. L., Porat, R., Clark, C. S., \& Green, D. P. (2021). Prejudice reduction: Progress and challenges. Annual review of psychology, 72, 533-560.

Peterson, E. R., Rubie-Davies, C., Osborne, D., \& Sibley, C. (2016). Teachers' explicit expectations and implicit prejudiced attitudes to educational achievement: Relations with student achievement and the ethnic achievement gap. Learning and Instruction, 42, 123-140.

Pettigrew, T. F. (2001). Intergroup relations and national and international relations. In R. Brown \& S. Gaertner (Eds.), Blackwell handbook of social psychology: Intergroup processes (pp. 514-532). Oxford, U.K.: Blackwell. 


\section{TEACHER RECOMMENDATION AND INEQUALITY}

Pietsch, M., \& Stubbe, T. C. (2007). Inequality in the transition from primary to secondary school: School choices and educational disparities in Germany. European Educational Research Journal, 6(4), 424-445.

Pit-ten Cate, I. M., Krolak-Schwerdt, S., \& Glock, S. (2016). Accuracy of teachers' tracking decisions: Short-and long-term effects of accountability. European Journal of Psychology of Education, 31(2), 225-243.

Pit-ten Cate, I. M., \& Glock, S. (2019). Teachers' implicit attitudes toward students from different social groups: a meta-analysis. Frontiers in psychology, 10, 2832.

Sprietsma, M. (2013). Discrimination in grading: Experimental evidence from primary school teachers. Empirical Economics, 45(1), 523-538.

Stephens, N. M., Fryberg, S. A., Markus, H. R., Johnson, C. S., \& Covarrubias, R. (2012). Unseen disadvantage: How American universities' focus on independence undermines the academic performance of first-generation college students. Journal of Personality and Social Psychology, 102(6), 1178-1197.

Südkamp, A., Kaiser, J., \& Möller, J. (2012). Accuracy of teachers' judgments of students' academic achievement: A meta-analysis. American Psychological Association.

Thornton, P., \& Ocasio, W. (2008). Institutional logic. In R. Greenwood, C. Oliver, K. Sahlin, \& R. Suddaby (Eds.), Sage handbook of organizational institutionalism (pp. 673-701). London, U.K.: SAGE.

Thys, Sarah. 2018. "The Tertiary Effect of Social Class. Multilevel Studies on the Role of the Primary School (Teacher) in Educational Decision-Making." PhD Thesis, Ghent University. 


\section{TEACHER RECOMMENDATION AND INEQUALITY}

Timmermans, A. C., Boer, H., \& Werf, M. P. (2016). An investigation of the relationship between teachers' expectations and teachers' perceptions of student attributes. Social Psychology of Education, 19(2), 217-240.

Timmermans, A. C., de Boer, H., Amsing, H. T. A., \& van der Werf, M. P. C. (2018). Track recommendation bias: Gender, migration background and SES bias over a 20 -year period in the Dutch context. British Educational Research Journal, 44(5), 847-874.

Timmermans, A. C., Kuyper, H., \& Werf, G. (2015). Accurate, inaccurate, or biased teacher expectations: Do Dutch teachers differ in their expectations at the end of primary education? British Journal of Educational Psychology, 85(4), 459-478.

Timmermans, A. C., van der Werf, M. G., \& Rubie-Davies, C. M. (2019). The interpersonal character of teacher expectations: The perceived teacher-student relationship as an antecedent of teachers' track recommendations. Journal of School Psychology, 73, 114-130.

Turetsky, K. M., Sinclair, S., Starck, J. G., \& Shelton, J. N. (2021). Beyond students: how teacher psychology shapes educational inequality. Trends in Cognitive Sciences

Uhlmann, E. L., \& Cohen, G. L. (2005). Constructed criteria redefining merit to justify discrimination.Psychological Science, 16, 474-480.

Urhahne, D., \& Wijnia, L. (2020). A Review on the Accuracy of Teacher Judgments. Educational Research Review, 100374.

Van de Werfhorst, H. G., \& Hofstede, S. (2007). Cultural capital or relative risk aversion? Two mechanisms for educational inequality compared 1. The British Journal of Sociology, 58(3), $391-415$. 


\section{TEACHER RECOMMENDATION AND INEQUALITY}

Van de Werfhorst, H. G., \& Mijs, J. J. (2010). Achievement inequality and the institutional structure of educational systems: A comparative perspective. Annual Review of Sociology, $36,407-428$.

Vanlommel, K., \& Schildkamp, K. (2018). How Do Teachers Make Sense of Data in the Context of High-Stakes Decision Making? American Educational Research Journal, 0002831218803891.

Wang, S., Rubie-Davies, C. M., \& Meissel, K. (2018). A systematic review of the teacher expectation literature over the past 30 years. Educational Research and Evaluation, 24(3-5), $124-179$.

Woessmann, Ludger, Elke Luedemann, Gabriela Schuetz, and Martin R. West. 2009. School Accountability, Autonomy and Choice Around the World. Cheltenham, UK: Edward Elgar. 
TEACHER RECOMMENDATION AND INEQUALITY

Table 1: overview of study outcomes on the influence of student demographic traits on teacher recommendations, accounting (at least) for student performance

\begin{tabular}{|c|c|c|}
\hline \multirow[b]{2}{*}{ Outcome } & \multicolumn{2}{|c|}{ Demographic traits } \\
\hline & High(er) socioeconomic status & Ethnically or racially disadvantaged groups \\
\hline Track recommendations & 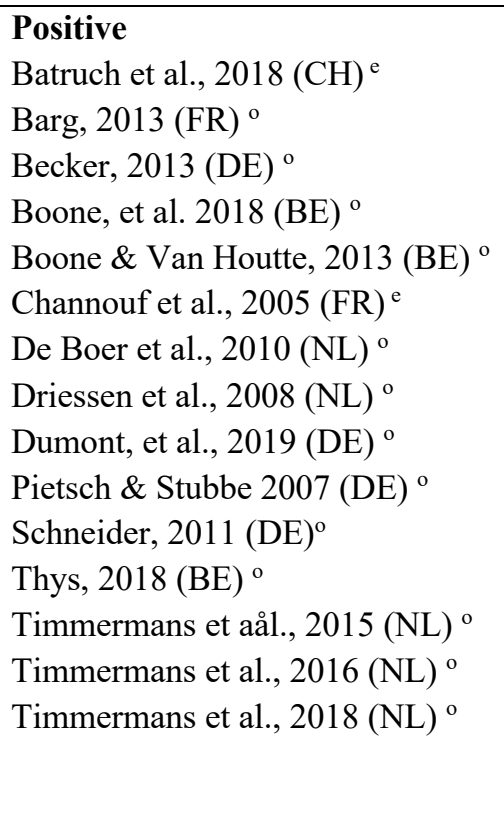 & 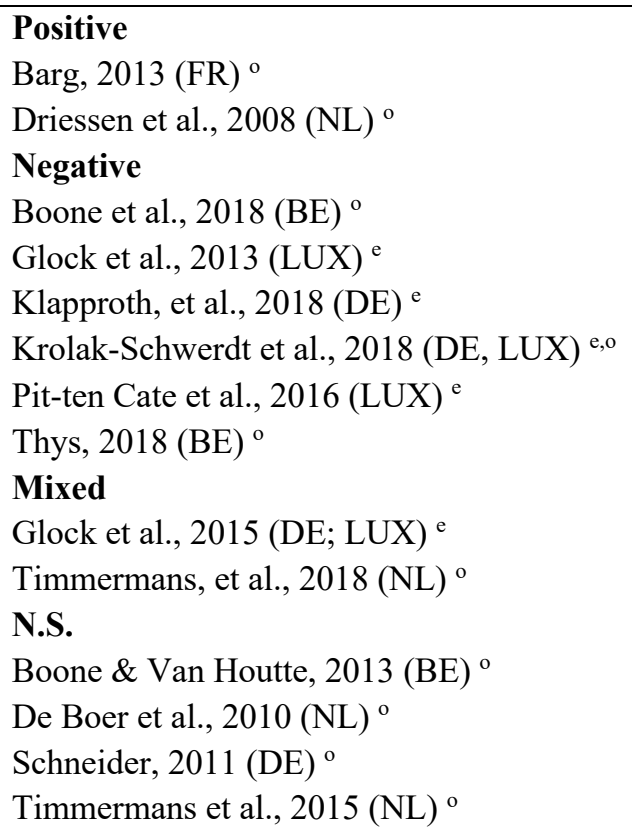 \\
\hline
\end{tabular}

Notes: The country of the study is indicated in brackets. N.S. refers to not statistically significant

${ }^{\circ}$ observational data; ${ }^{\mathrm{e}}$ experimental data 
TEACHER RECOMMENDATION AND INEQUALITY

Table 2: overview of study outcomes on the influence of student demographic traits on teacher expectations and judgements, accounting (at least) for student performance

\begin{tabular}{|c|c|c|}
\hline \multirow[b]{2}{*}{ Outcome } & \multicolumn{2}{|c|}{ Demographic traits } \\
\hline & High(er) socioeconomic status & Ethnically or racially disadvantaged groups \\
\hline Expectations of student performance & 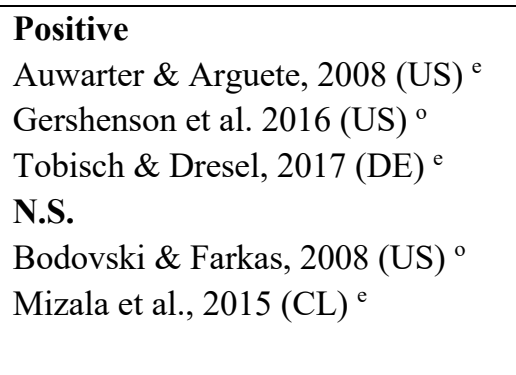 & 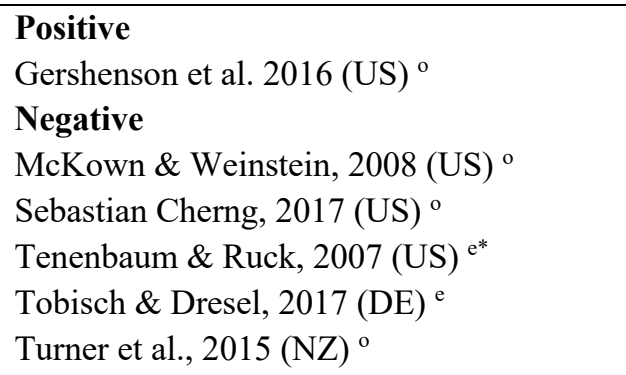 \\
\hline $\begin{array}{l}\text { Judgements of student performance or } \\
\text { ability }\end{array}$ & 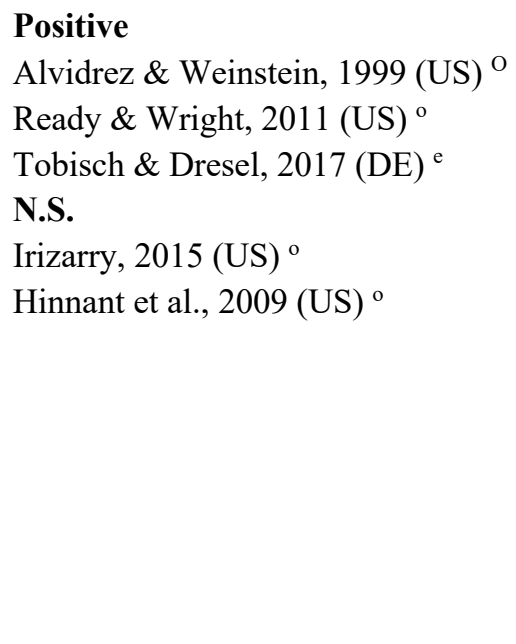 & 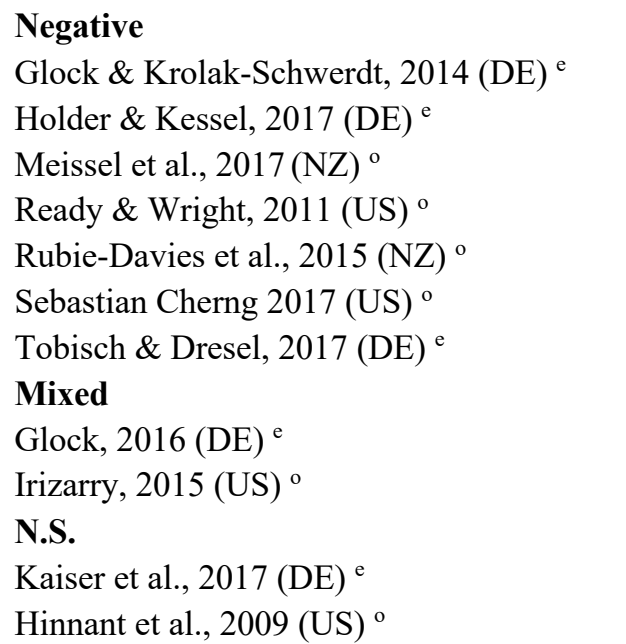 \\
\hline
\end{tabular}

Notes: The country of the study is indicated in brackets. N.S. refers to not statistically significant

${ }^{\mathrm{o}}$ observational data; ${ }^{\mathrm{e}}$ experimental data; ${ }^{\mathrm{e}}$ meta-study that relied on experimental data 
TEACHER RECOMMENDATION AND INEQUALITY 